\title{
CORRECTION
}

\section{Correction to: Afatinib is active in osteosarcoma cell lines}

\author{
Marlid Cruz-Ramos ${ }^{1,4} \cdot$ Yessica Zamudio-Cuevas ${ }^{2} \cdot$ Daniel Medina-Luna $^{2,5} \cdot$ Karina Martínez-Flores $^{2}$. \\ Gabriela Martínez-Nava ${ }^{2} \cdot$ Javier Fernández-Torres ${ }^{2} \cdot$ Alberto López-Reyes $^{6} \cdot$ Flavio Solca $^{3}$
}

Published online: 19 August 2020

(c) Springer-Verlag GmbH Germany, part of Springer Nature 2020

\section{Correction to: \\ Journal of Cancer Research and Clinical Oncology (2020) 146:1693-1700 \\ https://doi.org/10.1007/s00432-020-03220-y}

The title of the article is incorrectly published in the original article. The correct article title is "Afatinib is active in osteosarcoma cell lines".

Publisher's Note Springer Nature remains neutral with regard to jurisdictional claims in published maps and institutional affiliations.

The original article can be found online at https://doi.org/10.1007/ s00432-020-03220-y.

Marlid Cruz-Ramos

marlid.cruz@gmail.com

1 Oncology Translational Laboratory, Hospital Universitario Fundación Jiménez Díaz, Madrid, Spain

2 Laboratorio de Líquido Sinovial, Instituto Nacional de Rehabilitación, Mexico City, CDMX, México

3 Boehringer Ingelheim RCV GmbH \& Co KG, Vienna, Austria

4 Cátedras de CONACYT, Instituto Nacional de Cancerología, Avenida San Fernando 22, Belisario Domínguez Secc 16, Tlalpan, 14080 Mexico City, CDMX, México

5 Microbiology and Immunology Department, Faculty of Medicine, Dalhousie University, Halifax, NS, Canada

6 Laboratorio de Gerociencias, Instituto Nacional de Rehabilitación, Mexico City, CDMX, México 